\title{
Effect of Plant Spacing on Growth and Grain Yield of Soybean
}

\author{
Bhagirath S. Chauhan*, Jhoana L. Opeña \\ Weed Scientist and Assistant Scientist, Weed Science, Crop and Environmental Sciences Division, International Rice Research In- \\ stitute, Los Baños, Philippines. \\ Email: ${ }^{*}$ b.chauhan@irri.org
}

Received July $27^{\text {th }}, 2013$; revised August $29^{\text {th }}, 2013$; accepted September $15^{\text {th }}, 2013$

Copyright (C) 2013 Bhagirath S. Chauhan, Jhoana L. Opeña. This is an open access article distributed under the Creative Commons Attribution License, which permits unrestricted use, distribution, and reproduction in any medium, provided the original work is properly cited.

\begin{abstract}
In the Philippines, rice monoculture systems are common. Compared to these systems, the rice-soybean cropping system may prove more water-efficient and there is a trend of increasing soybean area in the response to water scarcity and need for crop diversification in the Philippines. A field study was conducted to evaluate the effect of row and plant to plant spacing $(20 \times 10,20 \times 5,40 \times 10$, and $40 \times 5 \mathrm{~cm})$ on growth and yield of soybean. Plant height was not influenced by the plant geometry. Spacing, however, influenced leaf area and shoot biomass of soybean. Plants grown at the widest spacing (i.e., $40 \times 10 \mathrm{~cm}$ ) produced lowest leaf area and shoot biomass at 6 and 12 weeks after planting. Leaf area and shoot biomass at other three spacing were similar. There was a negative and linear relationship between weed biomass and crop shoot biomass at 6 and 12 weeks after planting. Grain yield of soybean was not affected by plant geometry and it ranged from 1.3 to $1.9 \mathrm{t} \cdot \mathrm{ha}^{-1}$ at different spacing.
\end{abstract}

Keywords: Row Spacing; Plant to Plant Spacing; Leaf Area; Weed Biomass

\section{Introduction}

In the Philippines, rice (Oryza sativa L.) is the most important source of food, where it is mainly grown after intensive tillage in wet conditions. There are two seasons (dry and wet) and farmers grow rice in both seasons. In dry seasons, however, rice requires a huge amount of water for puddling (repeated tillage in wet conditions called puddling) and planting [1-3]. Farmers in Asia, including the Philippines, are expected to have limited irrigation water in the future to flood their rice fields [4]. There has been an increasing and competing demand for other water uses in urban areas. The risk of water scarcity may lead to changes in production systems to bring about less water demanding systems [5]. They may include dryseeded rice and crop diversification.

Soybean (Glycine max L.) is one of such crops, which can be grown in dry seasons. Compared to rice monoculture systems, the rice-soybean cropping system may prove more water-efficient in the Philippines. At present, soybean is not grown on a large area in the Philippines; however, there is a trend of increasing its area in the res-

${ }^{*}$ Corresponding author. ponse to water scarcity and need for crop diversification.

In different countries, soybean is grown at different row spacing $[6,7]$. The row spacing in soybean can vary from 19 to $76 \mathrm{~cm}$ [8]. Narrow row spacing is known to suppress weed growth by closing crop canopy earlier than wider row spacing $[7,9,10]$. Narrow row spacing may also increase available moisture to the crop, for example, corn (Zea mays L.) [11]. In soybean and corn, narrow row spacing was found to increase light interception $[6,12,13]$. Soybean yield can also be influenced by the plant to plant spacing within a crop row.

A computer search of published literature revealed that there is limited information available on the effect of row spacing and plant to plant spacing on the growth and grain yield of soybean in the Philippines. Plant geometry can also influence weed growth in the crop. A study was therefore conducted to evaluate the effect of plant geometry on the growth and yield of soybean at Los Baños, Philippines.

\section{Materials and Methods}

The study was conducted at the farm of the International Rice Research Institute, Los Baños, Laguna, Philippines. 
The experimental site had a clay loam soil with a $\mathrm{pH}$ of 6.8 and organic carbon of $1.2 \%$.

Two pre-sowing cultivations in dry soil conditions were performed before crop planting. Soybean seeds were planted by hand at four different plant geometries. The row and plant to plant spacing were $20 \times 10,20 \times 5$, $40 \times 10$, and $40 \times 5 \mathrm{~cm}$. Phosphorus $(\mathrm{P})$ and potassium (K) were applied before crop planting at $40 \mathrm{~kg} \mathrm{P}_{2} \mathrm{O}_{5} \mathrm{ha}^{-1}$ and $40 \mathrm{~kg} \mathrm{~K}_{2} \mathrm{O} \mathrm{ha}^{-1}$, respectively. Nitrogen $(\mathrm{N})$ as urea, was applied at $20 \mathrm{~kg} \mathrm{~N} \mathrm{ha}^{-1}$ at 4 weeks after planting (WAP) and $20 \mathrm{~kg} \mathrm{~N} \mathrm{ha}^{-1}$ at $8 \mathrm{WAP}$. The crop was planted on January 22, 2013, after mixing seed with rhizobium inoculant. The field was surface irrigated immediately after planting.

A pre-emergence application of pendimethalin $(1.0 \mathrm{~kg}$ ai ha ${ }^{-1}$ ) was used at $1 \mathrm{~d}$ after planting (DAP) to control weeds. After this, no weed control measures were taken. Pendimethalin was applied with a knapsack sprayer that delivered around $320 \mathrm{~L} \cdot \mathrm{ha}^{-1}$ spray solution through flat fan nozzles. No control measures were taken for insect and diseases.

In the field, the time taken for crop emergence, appearance of the first unifoliate leaf, appearance of the first trifoliate leaf, and start of flowering was observed. Immediately after crop emergence, six consecutive plants of soybean were tagged to measure their plant height and numbers of trifoliate leaves. These growth parameters were measured at 2, 4, 6, 8, and 10 WAP. Plant height was measured from ground level to the main stem tips. At 6 and $12 \mathrm{WAP}$, soybean plants in 1-meter row lengths were sampled from two places to measure leaf area $\left(\mathrm{cm}^{2} \cdot \mathrm{m}^{-2}\right)$ and shoot dry mass $\left(\mathrm{g} \cdot \mathrm{m}^{-2}\right)$. The biomass was measured after placing samples in an oven at $70^{\circ} \mathrm{C}$ for 72 hours. At the same periods (i.e., 6 and 12 WAP), weed biomass was also measured after taking samples from two quadrats of $40 \times 40 \mathrm{~cm}$. Soybean was harvested on April 30, 2013 from an area of $9.6 \mathrm{~m}^{2}$ and grain yield was converted to $t \cdot h \mathrm{~h}^{-1}$ at $16 \%$ moisture content.

The experiment was laid out in a randomized complete block design with three replications of each spacing treatment. The leaf area, shoot biomass, and grain yield data were analyzed using the least significant difference (LSD) at 5\% level of significance [14]. Plant height and leaf number data taken throughout the season were fitted to a three-parameter sigmoid model using SigmaPlot 10.0. A model, $y=a /\left\{1+e\left[-\left(x-W_{0}\right) / b\right]\right\}$ was used, where $y$ is the plant height or leaf (trifoliate) number at timex, $a$ is the maximum height $\left(\mathrm{cm} \cdot \mathrm{plant}^{-1}\right)$ or leaf number (plant ${ }^{-1}$ ), $W_{0}$ is the time (WAP) required to reach $50 \%$ of the maximum height or leaf number and $b$ is the slope. The relationship between weed biomass $\left(\mathrm{g} \cdot \mathrm{m}^{-2}\right)$ and crop biomass $\left(\mathrm{g} \cdot \mathrm{m}^{-2}\right)$ at 6 and 12 WAP was assessed using linear regression analysis (SigmaPlot 10.0).

\section{Results and Discussion}

Soybean plants emerged at 4 DAP. The first unifoliate leaf appeared at 6 DAP and first trifoliate leaf appeared at $12-13$ DAP. The crop started flowering at 42 DAP. There was a trend of increasing plant height of soybean at narrow row spacing and plant to plant spacing; however, it was statistically similar between treatments (Figure 1, Table 1). The maximum plant height (a) ranged from 72 to $94 \mathrm{~cm} \cdot$ plant $^{-1}$. The rate of development (slope $b)$ of height was also similar. The time taken to reach $50 \%$ of the maximum height $\left(W_{0}\right)$ ranged from 4.9 to 5.8 WAP, and it did not differ between different spacing. A previous study reported maximum heights of 107 to 117 $\mathrm{cm}$ for soybean and the time taken to reach $50 \%$ of the maximum height was 7 to 8 WAP [15].

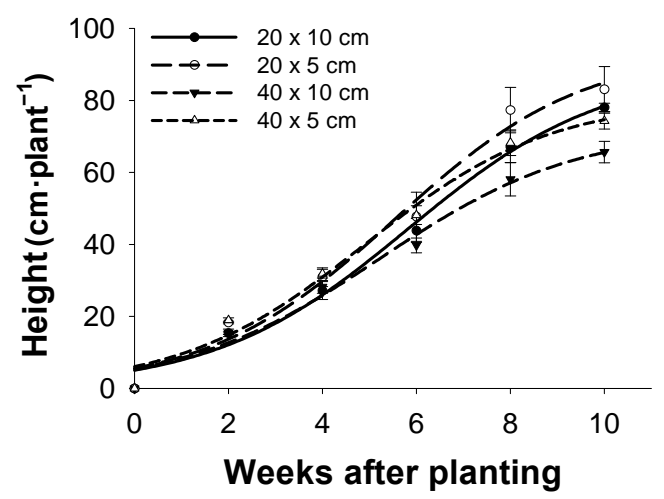

Figure 1. Effect of plant geometry (row and plant to plant spacing: $20 \times 10,20 \times 5,40 \times 10$, and $40 \times 5 \mathrm{~cm}$ ) on the height of soybean. A three-parameter sigmoid model was fitted to the height data over different times.

Table 1. Parameter estimates (standard error) of the threeparameter sigmoid model fitted to the plant height and leaf number data. The fitted model was

$y=a /\left\{1+e\left[-\left(x-W_{0}\right) / b\right]\right\}$, where $y$ is the plant height or leaf number at time $x, a$ is the maximum height $\left(\mathrm{cm} \cdot\right.$ plant $\left.^{-1}\right)$ or leaf number (plant $^{-1}$ ), $W_{0}$ is the time (WAP) required to reach $50 \%$ of the maximum height or leaf number, and $b$ is the slope.

\begin{tabular}{ccccc}
\hline Spacing $(\mathrm{cm})$ & \multicolumn{1}{c}{$A$} & $b$ & $W_{0}$ & $R^{2}$ \\
\hline \multicolumn{5}{c}{ Plant height } \\
$20 \times 10$ & $89.0(9.7)$ & $2.1(0.4)$ & $5.8(0.6)$ & 0.99 \\
$20 \times 5$ & $94.0(12.4)$ & $2.0(0.5)$ & $5.5(0.8)$ & 0.98 \\
$40 \times 10$ & $72.2(8.7)$ & $2.1(0.5)$ & $5.2(0.7)$ & 0.98 \\
$40 \times 5$ & $80.2(8.1)$ & $2.0(0.4)$ & $4.9(0.6)$ & 0.98 \\
& Leaf (trifoliate) number plant $^{-1}$ & \\
$20 \times 10$ & $17.5(1.1)$ & $1.2(0.3)$ & $5.0(0.3)$ & 0.95 \\
$20 \times 5$ & $12.6(0.7)$ & $1.2(0.3)$ & $4.3(0.3)$ & 0.97 \\
$40 \times 10$ & $24.4(0.5)$ & $1.4(0.1)$ & $5.5(0.1)$ & 0.99 \\
$40 \times 5$ & $16.2(1.1)$ & $1.2(0.3)$ & $4.8(0.4)$ & 0.99 \\
\hline \multicolumn{5}{c}{}
\end{tabular}


The highest numbers of trifoliate leaves $\left(24\right.$ plant $\left.^{-1}\right)$ were observed at $40 \times 10 \mathrm{~cm}$ spacing and they were significantly higher than those at other spacing (Figure 2, Table 1). The plants at other three spacing produced 13 to 18 trifoliate leaves plant ${ }^{-1}$. The rate of leaf development (slope $b$ ), however, was similar at different row and plant to plant spacing. The plants grown at the narrowest spacing (i.e., $20 \times 5 \mathrm{~cm}$ ) took $4.3 \mathrm{WAP}$ to reach $50 \%$ of the maximum leaf number plant $^{-1}$, whereas the plants grown at the widest spacing (i.e., $40 \times 10 \mathrm{~cm}$ ) took 5.5 WAP to reach $50 \%$ of the maximum leaf number plant ${ }^{-1}$ (Table 1).

Leaf area and shoot biomass of soybean were significantly affected by the row and plant to plant spacing. Plants grown at the widest spacing, that is $40 \times 10 \mathrm{~cm}$, produced lowest leaf area and shoot biomass and this was true at both sampling periods, that is 6 and 12 WAP (Table 2). At $6 \mathrm{WAP}$, for example, soybean produced a leaf area of $19,380 \mathrm{~cm} \cdot$ plant $^{-1}$ and a biomass of $95 \mathrm{~g} \cdot \mathrm{m}^{-2}$ when grown at $40 \times 10 \mathrm{~cm}$ spacing. Compared to $6 \mathrm{WAP}$, the leaf area reduced at $12 \mathrm{WAP}$ and this was mainly due to leaf senescence at crop harvest. Leaf area and shoot biomass at other three spacing were similar.

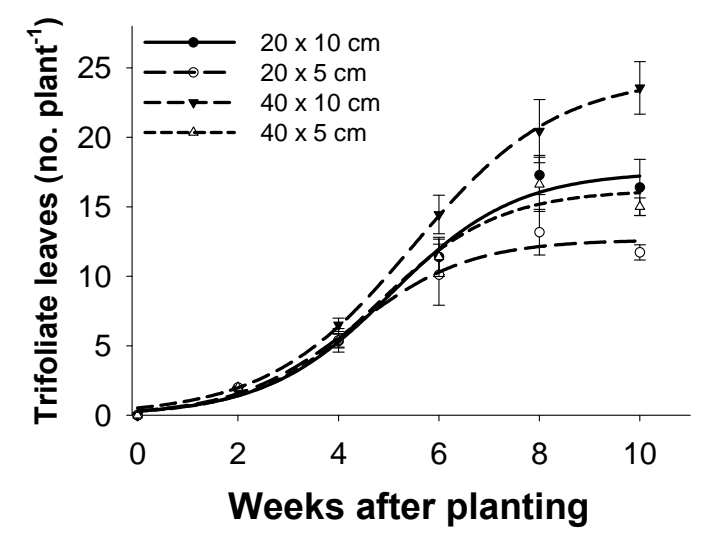

Figure 2. Effect of plant geometry (row and plant to plant spacing: $20 \times 10,20 \times 5,40 \times 10$, and $40 \times 5 \mathrm{~cm}$ ) on leaf production (number plant $^{-1}$ ) of soybean. A three-parameter sigmoid model was fitted to the data.

Table 2. Effect of spacing (row and plant to plant) on leaf area and crop biomass at 6 and 12 weeks after planting (WAP).

\begin{tabular}{ccccc}
\hline \multirow{2}{*}{$\begin{array}{c}\text { Spacing } \\
(\mathrm{cm})\end{array}$} & \multicolumn{2}{c}{ Leaf area $\left(\mathrm{cm}^{2} \cdot \mathrm{m}^{-2}\right)$} & \multicolumn{2}{c}{ Biomass $\left(\mathrm{g} \cdot \mathrm{m}^{-2}\right)$} \\
\cline { 2 - 5 } & 6 WAP & 12 WAP & 6 WAP & 12 WAP \\
\hline $20 \times 10$ & 30830 & 22380 & 149 & 778 \\
$20 \times 5$ & 38990 & 26070 & 198 & 710 \\
$40 \times 10$ & 19380 & 10700 & 95 & 517 \\
$40 \times 5$ & 24190 & 21220 & 174 & 730 \\
LSD & 8370 & 8750 & 51 & 145 \\
\hline
\end{tabular}

There was a negative and linear relationship between weed biomass and crop shoot biomass at 6 and 12 WAP (Figure 3). The correlation explained $44 \%$ of the variation in weed biomass at 6 WAP and $49 \%$ of the variation in weed biomass at 12 WAP. These results clearly suggest that increasing weed growth could affect crop biomass. By increasing crop biomass, a significant reduction in weed biomass can be achieved [16].

Grain yield of soybean was not influenced by the plant geometry (Figure 4). Grain yield ranged from 1.3 to 1.9 $\mathrm{t} \cdot \mathrm{ha}^{-1}$ at different spacing; however, the lowest grain yield was produced by plants at $40 \times 5 \mathrm{~cm}$. The results of this study suggest that plant spacing may influence leaf area and shoot biomass of soybean. However, the difference among grain yield was not significant. Such results

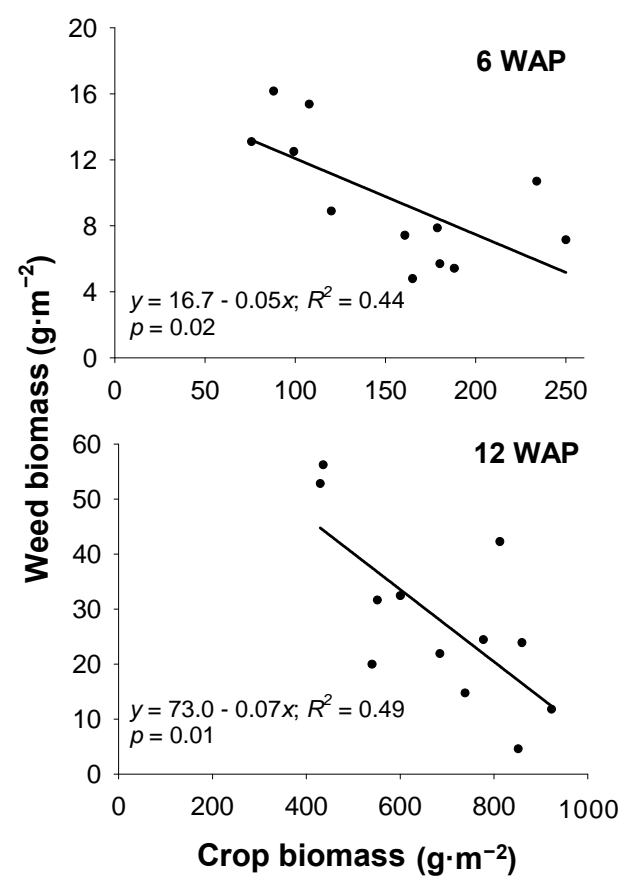

Figure 3. Relation between weed biomass and crop shoot biomass at 6 and 12 weeks after planting (WAP).

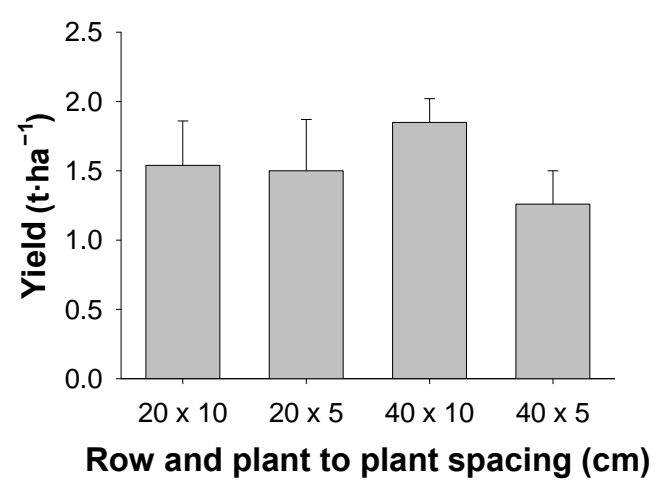

Figure 4. Effect of plant geometry (row and plant to plant spacing: $20 \times 10,20 \times 5,40 \times 10$, and $40 \times 5 \mathrm{~cm}$ ) on grain yield $\left(\mathrm{t} \cdot \mathrm{ha}^{-1}\right)$ of soybean. 
suggest that soybean can be grown successfully at both 20 and $40 \mathrm{~cm}$ row spacing. Narrow row spacing, however, may help in closing canopy earlier than wider row spacing. In a previous study, soybean planted in $18 \mathrm{~cm}$ rows was more competitive against weeds than those in $76 \mathrm{~cm}$ wide rows [17]. Similarly, Knezevic and colleagues suggested that planting soybean in wider rows reduced early season crop tolerance to weeds requiring earlier weed management programs than in narrower rows [7]. In water limited environments, narrow row spacing may enhance available moisture to soybean [11]. There is a need to study further the effect of plant geometry on the performance of different cultivars as cultivars differ in their height, leaf morphology, etc.

\section{REFERENCES}

[1] B. S. Chauhan, "Weed Ecology and Weed Management Strategies for Dry-Seeded Rice in Asia," Weed Technology, Vol. 26, No. 1, 2012, pp. 1-13. http://dx.doi.org/10.1614/WT-D-11-00105.1

[2] G. Mahajan, B. S. Chauhan and M. S. Gill, "Dry-Seeded Rice Culture in Punjab State of India: Lessons Learned from Farmers," Field Crops Research, Vol. 144, 2013, pp. 89-99. http://dx.doi.org/10.1016/j.fcr.2013.01.008

[3] G. Mahajan, B. S. Chauhan, J. Timsina, P. P. Singh and K. Singh, "Crop Performance and Water- and Nitrogen-Use Efficiencies in Dry-Seeded Rice in Response to Irrigation and Fertilizer Amounts in Northwest India," Field Crops Research, Vol. 134, 2012, pp. 59-70. http://dx.doi.org/10.1016/j.fcr.2012.04.011

[4] T. P. Tuong and B. A. M. Bouman, "Rice Production in Water-Scarce Environments, in Water Productivity in Agriculture: Limits and Opportunities for Improvements," In: J. W. Kijne, R. Barker and D. Molden, Eds., CABI Publishing, Wallingford, 2003, pp. 53-67. http://dx.doi.org/10.1079/9780851996691.0053

[5] M. C. R. Alberto, R. J. Buresh, T. Hirano, A. Miyata, R. Wassmann, J. R. Quilty, T. Q. Correa Jr. and J. Sandro, "Carbon Uptake and Water Productivity for Dry-Seeded Rice and Hybrid Maize Grown with Overhead Sprinkler Irrigation," Field Crops Research, Vol. 146, 2013, pp. 51-65. http://dx.doi.org/10.1016/i.fcr.2013.03.006

[6] J. E. Board and B. J. Harville, "Explanations for Greater Light Interception in Narrow- vs Wide-Row Soybean," Crop Science, Vol. 32, No. 1, 1992, pp. 198-202. http://dx.doi.org/10.2135/cropsci1992.0011183X0032000 $\underline{10041 \mathrm{x}}$

[7] S. Z. Knezevic, S. P. Evans and M. Mainz, "Row Spacing Influences the Critical Timing for Weed Removal in Soy- bean (Glycine max)," Weed Technology, Vol. 17, No. 4, 2003, pp. 666-673. http://dx.doi.org/10.1614/WT02-49

[8] S. M. Hock, S. Z. Knezevic, A. R. Martin and J. L. Lindquist, "Soybean Row Spacing and Weed Emergence Time Influence Weed Competitiveness and Competitive Indices," Weed Science, Vol. 54, No. 1, 2006, pp. 38-46. http://dx.doi.org/10.1614/WS-05-011R.1

[9] B. S. Chauhan and D. E. Johnson, "Implications of Narrow Crop Row Spacing and Delayed Echinochloa colona and Echinochloa crus-galli Emergence for Weed Growth and Crop Yield Loss in Aerobic Rice," Field Crops Research, Vol. 117, 2010, pp. 177-182. http://dx.doi.org/10.1016/j.fcr.2010.02.014

[10] B. S. Chauhan and D. E. Johnson, "Row Spacing and Weed Control Timing Affect Yield of Aerobic Rice," Field Crops Research, Vol. 121, 2011, pp. 226-231. http://dx.doi.org/10.1016/j.fcr.2010.12.008

[11] D. L. Karlen and C. R. Camp, "Row Spacing, Plant Population, and Water Management Effects on Corn in the Atlantic Coastal Plain," Agron Journal, Vol. 77, No. 3, 1985, pp. 393-398.

http://dx.doi.org/10.2134/agronj1985.0002196200770003 $\underline{0010 \mathrm{x}}$

[12] M. J. Ottman and L. F. Welch, "Planting Patterns and Radiation Interception, Plant Nutrient Concentration and Yield in Corn," Agron Journal, Vol. 81, 1989, pp. 167174. http://dx.doi.org/10.2134/agronj1989.0002196200810002 $\underline{0006 x}$

[13] M. Tollenaar, A. A. Dibo, A. Aguilera, S. F. Weise and C. J. Swanton, "Effect of Crop Density on Weed Interference in Maize," Agron Journal, Vol. 86, No. 4, 1994, pp. 591-595.

http://dx.doi.org/10.2134/agronj1994.0002196200860004 $\underline{0003 x}$

[14] GenStat 8.0, “GenStat Release 8 Reference Manual," VSN International, Oxford, 2005, $343 \mathrm{p}$.

[15] J. A. Torrion, T. D. Setiyono, K. G. Cassman, R. B. Ferguson, S. Irmak and J. E. Specht, "Soybean Root Development Relative to Vegetative and Reproductive Phenology," Agron Journal, Vol. 104, No. 6, 2012, pp. 1702-1709. http://dx.doi.org/10.2134/agronj2012.0199

[16] B. S. Chauhan, V. P. Singh, A. Kumar and D. E. Johnson, "Relations of Rice Seeding Rates to Crop and Weed Growth in Aerobic Rice," Field Crops Research, Vol. 121, 2011, pp. 105-115. http://dx.doi.org/10.1016/j.fcr.2010.11.019

[17] D. Mulugeta and D. Stoltenberg, "Increased Weed Emergence and Seed Bank Depletion by Soil Disturbance in a No-Till System," Weed Science, Vol. 45, 1997, pp. 234241. 